\title{
Correction to: A comprehensive review of the normal, abnormal, and post-operative MRI appearance of the proximal biceps brachii
}

\author{
Jeffrey Rosenthal ${ }^{1} \cdot$ My-Linh Nguyen ${ }^{2} \cdot$ Spero Karas $^{3} \cdot$ Michael Gottschalk $^{3} \cdot$ Charles Daly $^{3} \cdot$ Eric Wagner $^{3}$. \\ Adam D. Singer ${ }^{2}$
}

Published online: 16 November 2020

(C) ISS 2020

\section{Correction to: Skeletal Radiology (2020) 49:1333-1344} https://doi.org/10.1007/s00256-020-03415-x

In the original manuscript, this reads:

"Pulley instability can be diagnosed arthroscopically by the "ramp test," where a probe is placed on the LHB and pressure is applied. An intact sling will hold the LHB in place and at most allow the tendon to form a small $U$ shape (Fig. 11). However, when the sling is torn, the LHB tendon can sink into the joint with applied pressure, making a V shape (Fig. 12) [26]."

This should read:

"Pulley instability can be diagnosed arthroscopically by the "ramp test," where a probe is placed on the LHB and pressure is applied. An intact sling will hold the LHB in place and at most allow the tendon to form a V shape (Fig. 11). However, when the sling is torn, the LHB tendon can sink into the joint with applied pressure, making a U shape (Fig. 12) [26].”

Publisher's note Springer Nature remains neutral with regard to jurisdictional claims in published maps and institutional affiliations.

The online version of the original article can be found at https://oi.org/ 10.1007/s00256-020-03415-x

Adam D. Singer

Adamsinger82@gmail.com

Emory University School of Medicine, Atlanta, GA, USA

2 Department of Radiology and Imaging Sciences, Section of Musculoskeletal Imaging, Emory University Hospital, 59 Executive, Park South, 4th Floor Suite 4009, Atlanta, GA 30329, USA

3 Department of Orthopaedics, Emory University Hospital, Atlanta, GA, USA 